\title{
As unidades pluriverbais em dicionários: aspectos teóricos e metalexicográfıcos em publicações espanholas do século XX
}

DOI: http://dx.doi.org/10.21165/el.v50i2.2982

\section{Roosevelt Vicente Ferreira ${ }^{1}$ Renato Rodrigues-Pereira ${ }^{2}$}

\section{Resumo}

Com este artigo, apresentamos uma revisão bibliográfica a respeito dos preceitos teóricos que fundamentam a inserção das unidades pluriverbais nos dicionários. Para tanto, revisamos alguns trabalhos espanhóis de caráter metalexicográfico publicados no decorrer do século XX. As obras estudadas, Casares (1921), Menéndez Pidal (1945), Martínez (1947), Casares (1950), Haensch (1982), Haensch (1997) e Lara (1997) demonstram que a inclusão dos fraseologismos nos dicionários foi objeto de preocupação desde os primórdios do século XX, reforçando a necessidade, por parte dos lexicógrafos da atualidade, de estudos sobre esse universo léxico, devido a sua importância para a elaboração de dicionários linguísticos.

Palavras-chave: Lexicografia; Metalexicografia; dicionário; fraseologismo.

1 Universidade Federal do Mato Grosso do Sul (UFMS), Três Lagoas, Mato Grosso do Sul, Brasil; roosevf@uol.com.br; https://orcid.org/0000-0002-1546-8138

2 Universidade Federal do Mato Grosso do Sul (UFMS), Três Lagoas, Mato Grosso do Sul, Brasil; astrolabiorrp30@gmail.com; http://orcid.org/0000-0001-9870-3780 


\section{Unidades pluriverbales en diccionarios: aspectos teóricos y metalexicográficos en publicaciones españolas del siglo XX}

\section{Resumen}

Con este artículo, presentamos una revisión bibliográfica sobre los preceptos teóricos que subyacen a la inserción de unidades pluriverbales en los diccionarios. Para ello, revisamos algunas obras españolas de carácter metalexicográfico publicadas durante el siglo XX. Los trabajos estudiados, Casares (1921), Menéndez Pidal (1945), Martínez (1947), Casares (1950), Haensch (1982), Haensch (1997) y Lara (1997) demuestran que la inclusión de fraseologismos en los diccionarios fue objeto de preocupación desde principios del siglo XX, reforzando la necesidad, por los lexicógrafos de hoy, de estudios sobre ese universo léxico, debido a su importancia para la elaboración de diccionarios lingüísticos.

Palabras clave: Lexicografía; Metalexicografía; Diccionario; Fraseologismo.

\section{Introdução}

As origens da unidade lexical hiperonímica "dicionário" remontam à época renascentista, período em que novas línguas subjugaram a língua latina, ganhando os espaços onde essa dominava. Na época, precisamente em 1502, o italiano Calepino ${ }^{3}$ cunhou o termo Dictionarium, onde o sufixo arium, significando depósito, designa o local para a guarda das palavras.

Daquela época para a contemporaneidade, esse instrumento, responsável pelo depositário da língua e da cultura de uma comunidade linguística, passou por inúmeras transformações, acompanhando a evolução dos povos e os avanços tecnológicos, ora tentando retratar exaustivamente o léxico de uma determinada língua, ora apresentando os mais variados subconjuntos linguísticos que formam o emaranhado léxico de uma coletividade linguística.

Nesse labor, as decisões relacionadas à inserção dos subconjuntos léxicos nos dicionários de caráter geral, como os regionalismos, fraseologismos, tecnicismos, etc., mostram-se como um grande desafio para o fazer lexicográfico, tendo em vista as suas especificidades, quantidades e diferentes visões metalexicográficas.

3 Lexicógrafo italiano Ambrogio Calepino (1440-1511), mais conhecido pela forma latina de seu nome, Calepinus. 
As unidades pluriverbais ${ }^{4}$ formam o universo de interesse dos estudos da Fraseologia ${ }^{5}$, no entanto, a literatura pertinente demonstra-nos não haver um acordo formado entre os linguistas sobre o objeto de estudo desta área linguística, bem como um consenso sobre uma possível classificação das unidades e suas características linguísticas. Todavia, em termos gerais, observamos que, à sombra do aspecto formal, os estudos buscam o entendimento dos fenômenos de restrição combinatória léxica ou sintática, suas possibilidades e impossibilidades e os motivos de se apresentarem muitas vezes mais desejáveis. No universo da significação, as pesquisas de cunho léxico-semântico recaem sobre o fenômeno da integração total ou parcial, ou da não integração, dos significados dos elementos formantes da estrutura. Já no aspecto discursivo-pragmático, o alvo das pesquisas são as unidades léxicas complexas que constituem atos de fala por si mesmas e funcionam como enunciados com características de texto (provérbios, ditos populares, etc. $)^{6}$.

Os desencontros investigativos na área dos fraseologismos também refletem nos aspectos lexicográficos, acarretando sempre um desafio aos lexicógrafos a decisão de quais, como e onde devem ser localizadas e tratadas as combinações complexas na macroestrutura ou microestrutura de um dicionário. Os critérios para essa tomada de decisão aparecem em formas variadas nas obras metalexicográficas, sendo de suma importância uma percepção mais acurada desses pressupostos por parte dos estudiosos do fazer lexicográfico.

Nesse caminho, Porto Dapena (2002, p. 149, tradução nossa7) entende as unidades pluriverbais como subentradas e argumenta que "existe toda uma terminologia tradicional para denominar estas expressões fixas assim como suas variedades [...] cujas respectivas definições são muito difíceis de estabelecer". Já Castillo Carballo (2003, p. 89, tradução nossa ${ }^{8}$ ) alerta que a falta de estudos sérios a respeito dessas unidades, até a década de 1990, influenciou inevitavelmente a confecção das obras lexicográficas "de tal maneira que coletaram de modo bastante irregular as fraseologias, recorrendo, em muitos casos,

4 No decorrer deste trabalho utilizamos como sinônimos: unidades pluriverbais, unidades fraseológicas e fraseologismos, assim como outras terminologias usadas pelos teóricos pesquisados.

5 Considera-se como o embrião científico dos estudos das combinações léxicas as posturas publicadas na obra de Charles Bally, Traité de Stylistique Française, em 1909.

6 Como exemplo dessas possibilidades investigativas, citamos Zuluaga (1980), Corpas Pastor (1996) e Montoro Del Arco (2002).

7 No original: "[...] existe toda una terminología tradicional para denominar estas expresiones fijas así como sus variedades [...] cuyas respectivas definiciones por cierto resultan harto difíciles de establecer."

8 No original: "[...] de tal manera que estas han recogido, de modo bastante irregular, os fraseologismos, recurriendo, en muchos casos, a etiquetados pocos exhaustivos y vacilantes." 
a rótulos pouco exaustivos e hesitantes". Por sua vez, Garriba Escribano (2003) enfatiza que a maior preocupação está em determinar quais unidades devem aparecer na obra lexicográfica, e, mais recentemente, Krieger (2007) assevera que a perda quantitativa e qualitativa do léxico inventariado em uma obra lexicográfica aparece também por meio da insuficiência, ou até inexistência, de registro de sintagmas, expressões e fraseologias.

Dessa forma, percebemos a importância de uma pesquisa que proporcione uma ampla revisão bibliográfica, de forma cronológica, da teorização dos preceitos relacionados aos critérios para a inserção ${ }^{9}$ das unidades pluriverbais nas obras dicionarísticas da língua comum, como forma de possibilitar uma maior compreensão desses pressupostos nos dias atuais, reforçando assim a nossa responsabilidade linguística perante o fazer lexicográfico. Optamos como fontes para esta investigação publicações espanholas do século XX de cunho metalexicográfico, por verificarmos que as disposições lexicográficas espanholas oportunizadas nessas obras têm embasado importantes estudos lexicográficos do português brasileiro.

À vista disso, para a realização deste trabalho, discorremos sobre as teorizações que regem a lematização das unidades pluriverbais em obras lexicográficas espanholas, como forma de contribuir para os estudos dos fraseologismos em dicionários da língua portuguesa brasileira numa perspectiva metalexicográfica.

Amparando-nos em Rull (2017) que aponta que o nascimento da Lexicografia espanhola como disciplina científica aconteceu durante a segunda metade do século XX, dividimos nossa pesquisa em dois momentos distintos. No primeiro, discorremos sobre as pressuposições nas obras de Casares (1921), Menéndez Pidal (1945) e Martínez (1947) como representativas da primeira metade do século, e, no segundo, a respeito das publicações consideradas manuais metalexicográficos: Casares (1950), Haensch (1982), Haensch (1997) e Lara (1997).

\section{A Fraseologia na Lexicografia na primeira metade do século $X X$}

A publicação de 1921 intitulada Nuevo concepto del diccionario de la lengua traz o memorável discurso de Casares por ocasião de sua recepção na Real Academia Espanhola (RAE). Nesses escritos, Casares apresenta um conjunto de ideias para fundamentar e esclarecer a importância da constituição de um dicionário ideológico, tal como versa sobre as possibilidades de registro das unidades pluriverbais.

9 Não é objetivo desta pesquisa o estudo da composição de obras lexicográficas específicas de fraseologismos. 
O alvo das primeiras críticas por parte do linguista foi a definição de dicionário que a academia naquele tempo adotava: "livro em que, em ordem alfabética, contém e define ou explica todas as dicções de uma ou mais línguas, ou as de uma ciência, faculdade ou matéria determinada"10. Segundo Casares (1921, p. 11, tradução nossa ${ }^{11}$ ), o conceito deveria ser revisto para que fosse restituída ao dicionário "toda sua legítima amplitude, libertando-o de certa restrição que o desnaturaliza e empequenece".

De acordo com Casares (1921, p. 11, tradução nossa ${ }^{12}$ ), a ideia da recopilação dos vocábulos de um dicionário ter que ser apresentada em ordem alfabética soa absurda porque, dessa forma, "todos os idiomas privados do alfabeto carecerão para sempre disso".

Casares (1921, p. 93, tradução nossa ${ }^{13}$ ) defende, então, o formato do dicionário ideológico por possibilitar uma maior eficácia ao consulente ao apresentar uma visão mais ampla do campo semântico do lema, propiciando, dessa forma, o inventário da enorme riqueza fraseológica da língua espanhola, que normalmente se dispersa na ordenação alfabética e, não menos importante, a oportunidade que o novo conceito de dicionário apresentaria na lematização das unidades pluriverbais, enfatizando assim "a utilidade do sistema para a ordenação do imenso caudal paremiológico coletado e a ser coletado".

Em contestação às críticas de Casares sobre a ordenação alfabética, Maura y Montaner (1921) ${ }^{14}$ defende também o uso da ordenação usando como pano de fundo a importância da recopilação das unidades pluriverbais. Atesta a autoridade que esse tipo de organização na verdade facilita a busca das expressões da linguagem familiar (frases feitas e provérbios), que são formas desgovernadas de se falar e tomam significados excepcionais, muitas vezes vinculados às outras palavras. Assevera Maura y Montaner (1921, p. 116, tradução nossa ${ }^{15}$ ):

10 No original: "[...] libro en que, por orden alfabético, se contienen y definen o explican todas las dicciones de uno o más idiomas, o las de una ciencia, facultad o materia determinada.".

11 No original: "[...] toda su legítima amplitud, libertándolo de cierta restricción rutinaria que lo desnaturaliza y empequeñece.".

12 No original: "[...] habrán de carecer de éste por siempre jamás todas las lenguas privadas de alfabeto.".

13 No original: "[...] la utilidad del sistema para la ordenación del inmenso caudal paremiológico recogido y por recoger.".

14 Político e escritor espanhol. Foi o responsável pela contestação do discurso de Julio Casares.

15 No original: "Conviene, naturalmente, nuestro colega en la gran estimación que merecen estos modos adverbiales, frases hechas y proverbios; y si lo considera despacio, a causa de la heterogeneidad espiritual que observará en unos y en otras, conocerá que no cabe facilitarle al vulgo la busca, si no se le ofrecen catalogados alfabéticamente, según el método que tenemos establecido, u otro semejante a él.". 
Naturalmente, nosso colega concorda com a grande estima que esses modos adverbiais, frases e provérbios merecem; e se o considerar devagar, devido à heterogeneidade espiritual que observará em alguns, saberá que não é possível facilitar a busca pelas pessoas comuns, se elas não forem oferecidas em ordem alfabética, de acordo com o método que estabelecemos, ou outro semelhante a ele.

Em 1945, Menéndez Pidal prologa El diccionario que deseamos, inovador dicionário ilustrado de Samuel Gili Gaya (1945), no qual apresenta as diferenças entre o dicionário Tesoro de la lengua e o da Lengua hablada. Para o lexicógrafo, o primeiro se apresenta como um exaustivo depósito que custodia o bom uso da língua escrita do presente e do passado, e o segundo, mais seletivo, abriga o inventário da conversação diária, sendo mais enxuto e normativo. Menéndez Pidal (1945, p. XIV, tradução nossa ${ }^{16}$ ) sustenta que:

[...] tudo o que está literalmente escrito, exceto uma aberração puramente individual e extravagante, tudo o que é falado por um grupo da sociedade que não é totalmente sem instrução, deve ser incluído no dicionário, ora proceda do momento atual, ora venha de tempos passados.

Para justificar essa posição, Menéndez Pidal apresenta inúmeras orientações lexicográficas a respeito das unidades léxicas literárias, neologismos, arcaísmos, barbarismos, solecismos, estrangeirismos, marcações diatópicas e tecnicismos.

Em relação aos fraseologismos, apesar do dicionário de Gili Gaya dispor em seus apêndices de um capítulo sobre voces y locuciones latinas y extranjeras, Menéndez Pidal, paradoxalmente, não teoriza sobre esses aspectos lexicográficos no dicionário do "nosso desejo". Restringe-se a apresentar três exemplos de possíveis fraseologismos (empinar el codo, tirar de la oreja a Jorge, verlas venir) classificando-os como frases burlescas, destacando que esses fenômenos linguísticos devem ser indicados na obra lexicográfica em oposição às vozes eufemísticas.

Na mesma década, em 1947, Martínez publica o artigo Contribución a una teoría de la lexicografía na revista do Instituto Caro y Cuervo, intitulada de Thesaurus ${ }^{17}$, onde apresenta com muita propriedade a vasta história da Lexicografia espanhola e aborda várias questões lexicográficas, muitas delas baseadas em teóricos que o precederam.

16 No original: "[...] todo lo que literalmente se escribe, como no sea una aberración puramente individual y extravagante, todo lo que se habla por una agrupación de la sociedad no totalmente inculta, debiera ser recogido en el diccionario, ora proceda del momento actual, ora venga de tiempos pasados.".

17 Publicação periódica do Instituto Caro y Cuervo do Ministério de Educação Nacional da Espanha que difunde estudos sobre literatura, cultura, linguística teórica e aplicada. 
Acerca das suposições das unidades pluriverbais, pouco comentado pelo linguista, podemos extraira discussão sobreos pressupostossemânticosquedevemconsubstanciar os trabalhos do lexicógrafo. Destaca Martínez (1947, p. 113, tradução nossa ${ }^{18}$ ) o alerta feito por Körting (1884) ${ }^{19}$ sobre a atenção especial que o lexicógrafo deve ater aos fatos de que a maioria das palavras apresentam muitas e diferentes significações e que "a união desses vários significados não é acidental ou arbitrária, nem existe desde o início, mas historicamente foi formada de acordo com certas leis psicológicas". Dessa forma, enfatiza que o lexicógrafo deve distinguir a amplitude da significação de um vocábulo a partir do seu uso e comportamento na oração completa.

Diante dessas disposições, observamos que, no prelúdio do século $X X$, os aspectos fraseológicos já se apresentavam como preceitos dignos de discussão para um melhor "fazer lexicográfico". As inserções das unidades pluriverbais nos dicionários serviram de argumentos para Casares vender a ideia da eficácia e da eficiência de um dicionário ideológico, devido aos seus especiais aspectos semânticos e linguísticos. E, justamente, as unidades pluriverbais também serviram de contra-argumentos para que se rebatessem as críticas do linguista à ordenação alfabética.

Nesse caminho, na década de 1940, Menéndez Pidal (1945) e Martínez (1947) seguem rumos distintos em relação aos fraseologismos. O primeiro não toma partido em seus escritos de prologação no dicionário de Gili Gaya (1945), e o segundo, em uma esfera mais filosófica, enfatiza a preocupação que os lexicógrafos devem ter em relação às diferentes significações nas combinações léxicas, que segundo ele, são historicamente determinadas por leis psicológicas e contêm a forma espiritual impressa pelo estilo de cada falante.

\section{Os manuais metalexicográficos espanhóis na segunda metade do século $X X$}

Em 1950, publica-se a obra de Julio Casares, Introducción a la lexicografía moderna, considerada uma das pioneiras em termos metalexicográficos e apontada como o embrião dos fundamentos da Lexicografia espanhola como disciplina organizada. A obra apresenta inúmeros pressupostos teóricos, dentre eles, as bases teóricas dos estudos das unidades pluriverbais na vertente cervantina.

Primeiramente, Casares (1950) denomina as combinações léxicas de caráter estável de sintagmas. Essas combinações estáveis são classificadas pelo linguista em binárias

18 No original: "[...] la unión de estas diversas significaciones no es casual o arbitraria ni ha existido desde un principio sino que se ha formado históricamente según determinadas leyes psicológicas.".

19 Encyklopaedie und Mcthodologie der romanischen P/iüologie. Heilbronn, 1884. Zweiter Theil, p. 152. 
(nominais) e polinômios verbais. Na oportunidade, o linguista teoriza sobre a escolha do vocábulo que compõe a combinação que figurará como entrada no dicionário e o tratamento dessas estruturas no interior do verbete. De acordo com o lexicógrafo, as binárias só devem aparecer no dicionário quando confirmada sua estabilidade, por isso, nas palavras do autor, deve-se andar com muita cautela (hay que andarse con pies de plomo). No entanto, destaca Casares que normalmente não há dificuldade na colocação dessas unidades nos verbetes dos dicionários, pois aparecem como entrada o primeiro termo e, a partir dele, disponibiliza-se remissivas ao substantivo ou adjetivo que compõe a estrutura. Já sobre os polinômios verbais, formados por três ou mais termos, Casares (1950) argumenta que o dicionário da Academia adota uma hierarquia semântica em ordem decrescente (nome, verbo, adjetivo, pronome, advérbio, etc.) como critério para a escolha da unidade que aparecerá na ordenação alfabética, no entanto, hay vacilaciones. Outro critério indicado por Casares (1950, p. 98, tradução nossa ${ }^{20}$ ) é o proposto por Keniston (1946) que reforça que "as locuções não serão colocadas atendendo ao verbo se contiverem um substantivo, pronome, adjetivo ou advérbio". No entanto, entende o lexicógrafo que "é verdade que o procedimento moderno não é, em nossa opinião, mais vantajoso que o tradicional, e a consequência que deduzimos é que o problema colocado pela catalogação de expressões pluriverbais até agora não teve solução satisfatória"21.

Em relação ao tratamento das combinações no interior do verbete, Casares (1950, p. 99, tradução nossa ${ }^{22}$ ) destaca que, como muitas das denominações, principalmente das combinações binárias, são sinônimas, uma forma que se utiliza para evitar a repetição das definições, já que el orden alfabético es un desorden organizado, é o sistema de remissivas. Porém, o linguista levanta a questão "por que não colocar todos os nomes desses tipos em uma sequência, evitando as idas e vindas e permitindo ao leitor perceber, de relance, todas as equivalências existentes?".

Finalmente, na terceira parte da obra, dedicada por Casares a José Ortega y Gasset, o estudioso busca uma proposta de terminologia para as combinações de vocábulos que oferecem sentido unitário e uma disposição formal inalterável. Nessa oportunidade, o

20 No original: "[...] las locuciones no se colocarán atendiendo al verbo si contienen un nombre, pronombre, adjetivo o adverbio."

21 No original: "[...] es verdad que el procedimiento moderno no resulta, a nuestro entender, más ventajoso que el tradicional, y la consecuencia que deducimos es que el problema que plantea la catalogación de las expresiones pluriverbales no ha tenido hasta hoy solución satisfactoria.".

22 No original: "¿por qué no poner a continuación todos los nombres de esos tipos, evitando las idas y venidas y permitiendo al lector darse cuenta, en una ojeada, de todas las equivalencias existentes?". 
lexicógrafo teoriza sobre as locuções (locuciones), os provérbios (frases proverbiales), os rifões (refranes) e os modismos (modismos ${ }^{23}$ ).

Casares (1950, p. 167-184, tradução nossa ${ }^{24}$ ) denomina de locuções (locuciones) as combinações de vocábulos ou sintagmas que apresentam as características de inalterabilidade e de unidade de sentido. Para o linguista, locução é a "combinação estável de dois ou mais termos que funciona como elemento oracional e cujo sentido unitário consabido não se justifica, sem mais, como a soma do significado normal dos componentes". Em termos de classificação (ver figura 1), Casares propõe, sob o ponto de vista morfológico e funcional, a separação das locuções em dois blocos específicos. Às combinações léxicas que possuem um ou mais elementos com significado ou representação mental, mesmo que não seja o mesmo quando tratado individualmente, denomina de significantes. E, àquelas formadas por voces o partículas vacías de contenidos semánticos que possuem como ofício a humilde missão de estabelecer um nexo sintático, denomina de conexivas. Como aplicação da nova terminologia apresentada, Casares (1950, p. 184) propõe a substituição das marcações das abreviaturas nos verbetes, utilizadas até então, de expresión, frase e locución figurada o familiar pelas novas classificações então apresentadas.

Figura 1 - Visão geral das classificações das locuções propostas por Casares (1950)

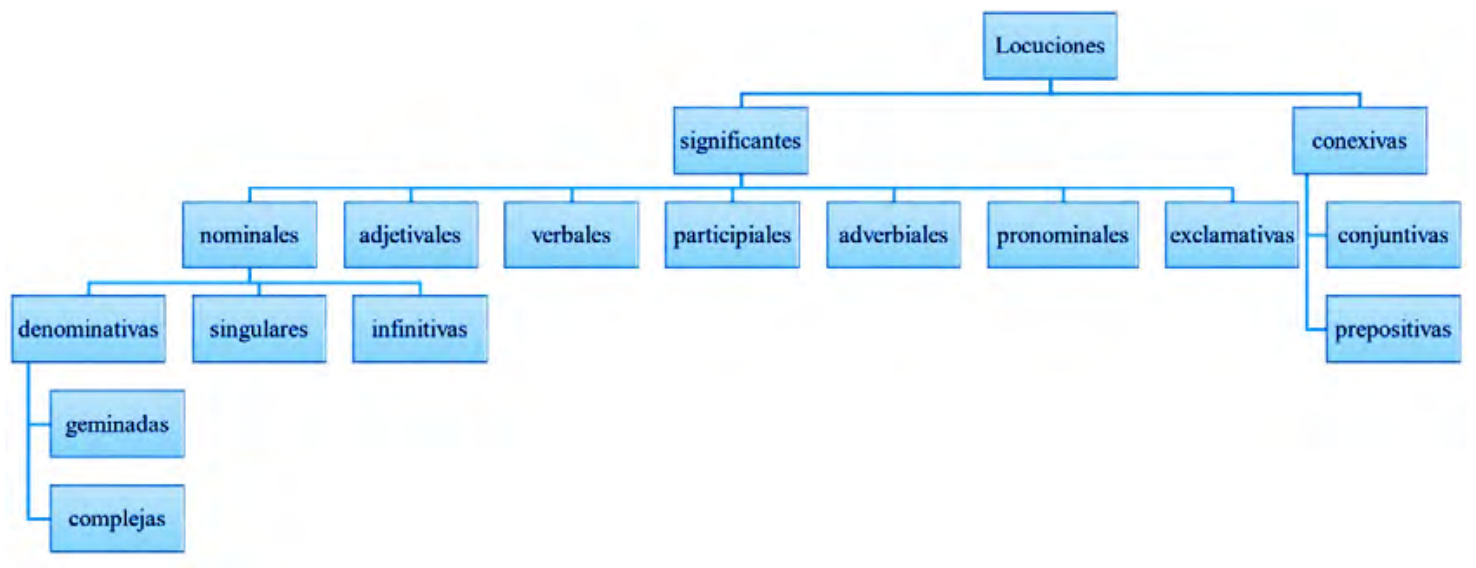

Fonte: Adaptado de Casares (1950, p. 183)

23 Como não é objetivo deste trabalho apresentar as bases teóricas dos estudos fraseológicos, e sim focarmos nos aspectos de natureza lexicográfica, não apresentamos de forma exaustiva os conceitos e classificações das unidades pluriverbais propostas por Casares (1950). Atemonos às pequenas conceituações distintivas e destacamos os preceitos lexicográficos das locuciones, frases proverbiales e refranes. Não discutimos os pressupostos sobre os modismos, esquadrinhados em três capítulos na obra, por acharmos que o autor não apresenta aspectos de interesse lexicográfico e por essas combinações pluriverbais se aproximarem muito das outras discutidas.

24 No original: "[...] combinación estable de dos o más términos que funciona como elemento oracional y cuyo sentido unitario consabido no se justifica, sin más, como una suma del significado normal de los componentes". 
Para o teórico, os provérbios (a más moros, más ganancia; nadie las mueva que estar no pueda con Roldán a prueba) são entidades léxicas autônomas que não servem de elementos sintáticos em uma oração, assim como as locuções. O valor expressivo dessa estrutura léxica não está nas imagens que possa conter, mas sim no paralelismo que se estabelece entre o momento atual e outro no passado, ou seja, na maioria dos casos, o que se transforma em provérbio é um fato ou discurso que ficou famoso em um acontecimento histórico real ou imaginário ou em atos ligados a um personagem desse feito. Os nominados de rifões (al freír será el reír, y al pagar será el llorar) são frases completas que apresentam sentido direto ou alegórico e que, de forma elíptica, expressam pensamentos, experiências e ensinamentos relacionando, normalmente, duas ideias.

Em termos lexicográficos, destaca Casares (1950) que só interessa à Lexicografia os rifões que encerram um determinado conteúdo ideológico, originando uma nova entidade léxica indivisível, ou seja, que se comportam como paremias, descartando, dessa forma, aquelas que são semanticamente somatórias dos significados das partes que as compõem. Para os provérbios, Casares (1950) sugere o tratamento lexicográfico daqueles cujos significados não são tão claros e que vão ficando mais opacos no decorrer do tempo e destaca a necessidade de estudo caso a caso e a utilização de boas abonações literárias.

No ano de 1982, coordenado por Günther Haensch e com a participação dos lexicógrafos Lothar Wolf, Stefan Ettinger e Reinhold Werner, publica-se um manual metalexicográfico dos mais importantes e completos da língua espanhola: La lexicografía. Haensch (1982) destaca a importância da obra por apresentar uma síntese da linguística moderna e por sustentar um detalhamento significativo de aspectos práticos para a elaboração de uma obra lexicográfica.

Na verdade, a completude do manual não passa só por esses aspectos. O seu conteúdo teórico, tanto de aspectos linguísticos, quanto no lexicográfico (tipologias das obras, aspectos definicionais, etc.) é de uma profundidade que faz da obra um guia imprescindível de fundamentação do fazer dicionarístico.

Para Werner (1982, p. 93, tradução nossa ${ }^{25}$ ), reserva-se o termo lexicografia para "todo domínio da descrição léxica que se concentre no estudo e na descrição dos monemas e simonemas individuais dos discursos individuais, dos discursos coletivos, dos sistemas linguísticos individuais e dos sistemas linguísticos coletivos". Como monemas, entendese as unidades significativas mínimas e como simonemas os significantes compostos de vários monemas. Os simonemas, destaca o linguista, quando lexicalizados, devem

25 No original: "[...] todo dominio de la descripción léxica que se concentre en el estudio y la descripción de los monemas y sinmonemas individuales de los discursos individuales, de los discursos colectivos, de los sistemas lingüísticos individuales y de los sistemas lingüísticos colectivos.". 
ser considerados como parte do léxico e sua descrição de conteúdo não deve ser atribuída à gramática, mas sim codificada nas obras lexicográficas por serem unidades fraseológicas lexicalizadas, devendo, dessa forma, serem lematizados. No entanto, o lexicógrafo chama a atenção para o fato de que, na prática lexicográfica, como solução pragmática, essas unidades não aparecem nos dicionários semasiológicos como lemas próprios, mas ancorados em uma das palavras que as compõem. De acordo com o linguista, esse pragmatismo não gera sérios problemas aos consulentes, entretanto, a falta de princípios mais específicos deve ser alvo de críticas em muitos dicionários:

Quem usa o dicionário deve frequentemente consultar, como tentativa, lemas que correspondem a várias partes componentes de uma unidade fraseológica, porque o lexicógrafo esqueceu de estabelecer, cumprir ou explicar uma regra que determine sob qual parte componente de uma unidade fraseológica figura esta. (WERNER, 1982, p. 230, tradução nossa26).

Nesse caminho, somam-se a esse empecilho mais dois problemas de maior monta que permeiam o desafio da definição de quais unidades devem ser lematizadas: a decisão de quais simonemas devem ser considerados lexicalizados e quais dos muito habituais devem ser incorporados juntamente com esses últimos nos dicionários.

Essa problemática é tratada por Ettinger (1982, p. 249-251, tradução nossa27) que sustenta que, nos dicionários, dependendo de sua extensão, além das palavras isoladas, são vocabularizadas as combinações de palavra-chave com outros lexemas, principalmente "quando a esta combinação corresponde um significado que não se pode deduzir diretamente dos significados das partes componentes". Tomando como base o caráter da fixidez entre os lexemas, o estudioso apresenta dois grandes grupos de unidades léxicas pluriverbais: as colocações e as combinações fixas de lexemas, e questiona até que ponto e como devem essas unidades ser tratadas nos dicionários.

Como colocação, entende Ettinger (1982) que é a tendência sintático-semântica (podendo também haver critérios extralinguísticos e práticos) das palavras isoladas de uma língua em adotar um número limitado de combinações. Os estudos dessas unidades são complexos e dessa forma, para o linguista, devem preceder sempre de uma detalhada análise semasiológica em todos os níveis linguísticos e os resultados revisados por falantes nativos. Já as combinações fixas de lexemas (unidades fraseológicas, modismos, unidades do discurso repetido, etc.) estão sujeitas à restrição rigorosa de uso porque

26 No original: "El que usa el diccionario debe consultar a menudo, a modo de intento, lemas que corresponden a varias de las partes componentes de una unidad fraseológica, porque el lexicógrafo ha olvidado establecer, cumplir o explicar una regla que determine bajo que parte componente de una unidad fraseológica figura ésta.".

27 No original: "[...] cuando a esta combinación le corresponde un significado que no se puede deducir directamente de los significados de las partes componentes.". 
não são livremente intercambiáveis e não apresentam uma classificação linguística convincente e coerente, bem como, critérios válidos para uma classificação adequada, sem que haja interferência entre as diferentes categorias propostas.

Entretanto, Ettinger (1982) enfatiza a necessidade de se aumentar o número das combinações léxicas nos dicionários, apesar do desafio das classificações, como forma de melhorar a qualidade das obras lexicográficas e defende a indispensabilidade das unidades fraseológicas figurarem em um dicionário bilíngue, não só na língua de partida, mas também na de chegada, para que não haja desfiguração do seu uso linguístico.

Nos aspectos práticos da elaboração de dicionários, Haensch (1982) discute sobre la parte sintagmática del artículo. O linguista argumenta sobre duas problemáticas que os lexicógrafos enfrentam, quais sejam: i) a distribuição das relações sintagmáticas no conjunto da macroestrutura; ii) a distribuição das unidades pluriverbais no interior do verbete.

Em i), o linguista apresenta a solução sob o ponto de vista da facilidade de uso do repertório léxico. Dessa forma, sugere a inserção das combinações léxicas em todos os lemas das partes que as compõem, com exceção das palavras gramaticais. Esclarece ainda que, caso não seja possível por falta de espaço, deve-se adotar um sistema que atribua a combinação a um só lema, podendo ser a primeira palavra da estrutura, o primeiro vocábulo, segundo a ordem alfabética dos componentes, ou pelo estabelecimento de uma prioridade entre as categorias gramaticais.

No que se refere à segunda problemática, ii) a distribuição das unidades pluriverbais no interior do verbete, o lexicógrafo alega que as estruturas complexas podem aparecer logo após o lema ou preceder as subentradas, quando são consideradas indicações gramaticais. No entanto, destaca que normalmente se concentram ao final da microestrutura, logo após as acepções das definições nos dicionários semasiológicos. Haensch (1982, p. 504, tradução nossa ${ }^{28}$ ) ressalta ainda que "a diferenciação entre relações sintagmáticas tratadas no corpo do verbete e as que devem figurar na ampliação sintagmática deste é difícil e pode ser subjetiva e arbitrária. Alguns dicionários simplificaram o problema ao tratar todas as relações sintagmáticas léxica ao final". Entretanto, para o linguista, a controversa desse paliativo está no fato de que muitas das relações sintagmáticas, ao aparecerem ao final do verbete, já terão sido tratadas nas subentradas, e nesse caso, poderá não sobrar unidades para a colocação ao final do verbete.

28 No original: "La diferenciación entre relaciones sintagmáticas tratadas en el cuerpo del artículo y las que deben figurar en la ampliación sintagmática de éste es difícil y puede ser subjetiva y arbitraria. Algunos diccionarios han simplificado el problema al tratar todas las relaciones sintagmáticas léxica al final.". 
Como uma solução prática, o estudioso sugere o registro em uma subentrada das relações sintagmáticas que possuam um vínculo direto e estreito com a acepção, deixando para o final do verbete aquelas combinações com outras unidades não registradas nas subentradas e as que se usam metaforicamente. Outra saída proposta é a reunião de todas as unidades em uma só parte do verbete, independente das acepções, estruturandoas em um esquema de apresentação fixa, por exemplo, seguindo a categoria gramatical ou utilizando outros símbolos para a sua ordenação. De qualquer forma, para ambos os casos, tais decisões precisam ser tomadas e explicadas, de forma detalhada, na parte introdutória do inventário lexicográfico, como explica Haensch (1982).

Em 1997, temos a editoração de importante obra de Günther Haensch: Los diccionarios del español en el umbral del siglo XXI. O exemplar enumera uma exaustiva classificação exemplificada dos inúmeros dicionários espanhóis, com observações críticas positivas e negativas de tais repertórios, mas sem reflexões metalexicográficas mais apuradas.

Em relação ao objeto de investigação deste trabalho, o lexicógrafo argumenta que os dicionários registram, além das unidades léxicas univerbais, também as unidades pluriverbais fixadas pelo uso e lexicalizadas. Haensch (1997, p. 39, tradução nossa ${ }^{29}$ ) destaca que, diferentemente dessas últimas, existem as unidades chamadas de colocaciones que são combinações habituais de palavras fixadas pelo uso, e enfatiza que "os dicionários gerais deveriam levar em conta muito mais, até o momento, as unidades pluriverbais e as colocações, ainda que tenha que sacrificar palavras isoladas (unidades univerbais) menos usuais".

Também em 1997, encerrando o século XX, publica-se a obra de Luís Fernando Lara. 0 livro se apresenta como um manual linguisticamente teórico, de verbalização densa, e de atualização das resoluções metalexicográficas da língua espanhola. A despeito do grande aporte teórico, em relação às combinações léxicas não encontramos conteúdos teóricos pertinentes, existindo apenas uma pequena observação. Lara (1997, p. 113, tradução nossa ${ }^{30}$ ) destaca que "as colocações do vocábulo em seus ambientes sintagmáticos mais característicos" fazem parte do verbete em determinados dicionários monolíngues. A cientificidade que revestiu a Lexicografia na segunda metade do século XX proporcionou visões mais aprofundadas acerca da inserção dos fraseologismos nos dicionários, tanto na esfera teórica, como metalexicográfica. Notamos, dessa forma, na obra representativa da década de 1950 uma coletânea de relevância linguística e lexicográfica, em que Casares (1950) proporciona uma teorização aprofundada das combinações pluriverbais de caráter estável. Primeiramente aponta os aspectos lexicográficos sobre a escolha do vocábulo que figurará como entrada e o tratamento das combinações no interior do

29 No original: "[...] los diccionarios generales deberían tener en cuenta, mucho más que hasta ahora, las unidades pluriverbales y las colocaciones, aunque haya que sacrificar palabras aisladas (unidades univerbales) menos usuales.".

30 No original: "[...] las colocaciones del vocablo en sus entornos sintagmáticos más característicos [...].". 
verbete. Na sequência, em homenagem a José Ortega y Gasset, o lexicógrafo apresenta a sugestão das terminologias, suas classificações e fundamentos teóricos das locuções (locuciones), dos provérbios (frases proverbiales), dos rifões (refranes) e dos modismos (modismos). Essas colocações configuram, até os dias atuais, as bases para os estudos da Fraseologia, tanto espanhola, como de outras vertentes.

Por sua vez, éinegável a riqueza da obra coordenada por Haensch (1982). Além de preciosos aspectos teóricos da linguística contemporânea, em sua mais necessária profundidade, o exemplar nos proporciona todos os aspectos necessários para o entendimento teórico e prático da formulação de uma obra dicionarística, sendo, dessa forma, um manual de renome na vertente lexicográfica espanhola. Muitas são as estruturações fraseológicas que são discutidas na obra, como os problemas da lematização que abrangem a determinação de qual palavra representará a combinação léxica como lema; a falta de uma explicação da regra na macroestrutura; as dificuldades das classificações das unidades léxicas em colocações e combinações fixas de lexemas, sendo sempre necessária uma detalhada análise linguística; os desafios de se aumentar o número das combinações léxicas nos dicionários, apesar de todos entraves discutidos, como forma de melhorar a qualidade das obras; e a distribuição das unidades dentro da macroestrutura e do verbete. Tomadas todas as decisões, é imprescindível que o lexicógrafo não se esqueça das informações necessárias ao consulente na parte introdutória da obra.

Finalmente, os manuais da década de 1990, de Haensch (1997) e Lara (1997), são mais tímidos no tratamento das unidades pluriverbais nos dicionários. No caso de Haensch, entendemos a pouca fundamentação metalexicográfica, por sabermos que não é o objetivo maior da obra. Entretanto, o lexicógrafo considera a divisão das combinações em colocações, que são frequentes, mas não lexicalizadas, e pluriverbais fixadas pelo uso, que são lexicalizadas, defendendo a inserção de ambas nos dicionários, mesmo que se tenha que sacrificar as unidades univerbais menos usuais. Nesse caminho, o manual de Lara, apesar do grande aporte teórico, não apresenta conteúdos em relação às unidades pluriverbais, apenas uma pequena lembrança de sua existência nos dicionários monolíngues.

\section{Conclusão}

Em nossa concepção, foi alcançado a contento o objetivo maior de se realizar, por meio de uma revisão bibliográfica, um exame cronológico da teorização dos princípios relacionados à inserção das unidades pluriverbais nos dicionários. Este trabalho nos proporcionou um olhar amplamente novo a respeito das combinações léxicas nas obras lexicográficas, graças às variadas visões metalexicográficas encontradas nas publicações pesquisadas. 
Diante de tais fundamentos, notamos que algumas publicações se apresentam como verdadeiros repertórios teóricos que embasam os estudos das unidades fraseológicas na língua espanhola, como é o caso de Casares (1950) e Haensch (1982). Os fundamentos propostos por Casares sustentam, ainda hoje, as bases teóricas dos estudos das unidades pluriverbais na língua espanhola. As demais publicações trazem o assunto de maneira mais sumária, porém, não menos importante.

Os pressupostos apresentados com base nos lexicógrafos mencionados alhures nos possibilitam a conclusão de que o campo das unidades fraseológicas fez parte das grandes preocupações lexicográficas dos teóricos espanhóis no decorrer do século XX, caracterizando-se como um aspecto dos estudos lexicográficos de muita importância.

Outrossim, ressaltamos a relevância de mais estudos nesta seara, como forma de proporcionar mais reflexões teóricas em profundidade e com vistas a oferecer mais parâmetros organizacionais cada vez mais fundamentados pelos princípios teóricos e metodológicos da Lexicografia contemporânea que, por sua vez, almeja facilitar repertórios lexicográficos elaborados sempre em conformidade com o tipo de dicionário e as necessidades dos potenciais consulentes.

\section{REFERÊNCIAS}

BALLY, C. Traité de Stylistique Française. v. 1. 50 ed. Genève : Libraire de l'Université George \& Cie S.A., 1970 [1909].

CASARES, J. Introducción a la lexicografía moderna. Madrid: CSIC, 1950.

CASARES, J. Nuevo concepto del diccionario de la lengua. Discurso leído en el acto de recepción de J. Casares como miembro de la Real Academia Española. Madrid: G. Koehler, 1921.

CASTILLO CARBALLO, M. A. La macroestructura del diccionario. In: MEDINA GUERRA, A. (coord.). Lexicografía española. Barcelona: Ariel Lingüística, 2003.

CORPAS PASTOR, G. Manual de fraseología española. Madrid: Gredos, 1996.

GARRIBA ESCRIBANO, C. La microestructura del diccionario: las informaciones lexicográficas. In: MEDINA GUERRA, A. (coord.). Lexicografía española. Barcelona: Ariel Lingüística, 2003. p. 103-126. 
GAYA, S. G. Diccionario General Ilustrado de la lengua española. Barcelona: Editorial SPES, 1945.

HAENSCH, G.; WOLF, L.; ETTINGER, S.; WERNER, R. La lexicografía. De la lingüística teórica a la lexicografía práctica. Madrid: Credos, 1982.

HAENSCH, G.; WOLF, L.; ETTINGER, S.; WERNER, R. Los diccionarios del español en el umbral del siglo XXI. Salamanca: Ediciones Universidad de Salamanca, 1997.

KENISTON, H. Tentative Dictionary of Medieval Spanish. Chapel Hill, 1946.

KRIEGER, M. G. O dicionário de língua como potencial instrumento didático. In: ISQUERDO, A. N.; ALVES, I. M. (org.). As ciências do léxico: lexicologia, lexicografia e terminologia.v. III. Campo Grande: Editora UFMS, 2007. p. 295-309.

LARA, L. F. Teoría del diccionario monolingüe. México: El Colegio de México, 1997.

MARTÍNEZ, F. A. Contribución a una teoría de la lexicografía española. Thesaurus. Revista del Instituto Caro y Cuervo. III. 1947.

MAURA y MONTANER, A. Contestación. In: CASARES, J. Nuevo concepto del diccionario de la lengua. Discurso leído en el acto de recepción de J. Casares como miembro de la Real Academia Española. Madrid: G. Koehler, 1921. p. 96-118.

MENÉNDEZ PIDAL, R. El diccionario que deseamos. Prólogo al diccionario general ilustrado de la lengua española. 1945.

MONTORO DEL ARCO, E. T. Teoría fraseológica de las locuciones particulares. Las locuciones prepositivas, conjuntivas y marcadoras en español. Frankfurt: Peter Lang, 2002.

PORTO DAPENA, J. A. Manual de técnica lexicográfica. Madrid: Arco Libros, 2002.

RULL, A. N. Hacia una nueva conceptualización de diccionarios pedagógicos de español. In: Estudios de Lexicología y Lexicografía. Homenaje a Eloina Miyares Bermúdez. (2017).

ZULUAGA, A. Introducción al estudio de las unidades fijas. Frankfurt am Maim: Peter Lang, 1980. 